\title{
Rotura vesical como causa de pseudo insuficiência renal aguda
}

\author{
Bladder rupture causing pseudo acute renal failure
}

Luciana Andrea Avena Smeilia, Elizabeth In Myung Kimª, Carlos Eduardo Marcello ${ }^{a}$, Leonardo Bianqui ${ }^{b}$, João Augusto dos Santos Martines ${ }^{c}$, Américo Thoshiaki Sakaid

Smeili LAA, Kim EIM, Marcello CE, Bianqui L, Martines JAS, Sakai AT. Rotura vesical como causa de pseudo insuficiência renal aguda. Autopsy Case Rep [Internet]. 2011;1(3):47-52. http://dx.doi.org/10.4322/acr.2011.008

\section{RESUMO}

A rotura vesical é uma condição rara associada a significante morbidade e mortalidade.É classificada em traumática, não traumática ou espontânea e idiopática, as duas últimas mais raras. O quadro clínico inicial é inespecífico seguido por desconforto em abdome inferior, oligúria, hematúria, e posterior ascite. As alterações laboratoriais simulam o quadro de insuficiência renal aguda e ocorrem pelo mecanismo chamado de auto diálise reversa, com absorção de excretas através da membrana peritoneal. Os autores descrevem um caso de rotura vesical em bexiga morfologicamente e funcionalmente normal associada à ingesta alcoólica em homem jovem sem doenças prévias, que se manifestou com ascite volumosa, desconforto abdominal e pseudo insuficiência renal. O diagnóstico foi feito através da tomografia computadorizada por multidetectores de abdome confirmada pelo achado de laceração de $7 \mathrm{~cm}$ na laparotomia.

Unitermos: Bexiga urinária; Diálise; Insuficiência renal; Ascite.

\section{ABSTRACT}

Bladder rupture is a rare condition associated with significant morbidity and mortality. It is classified into traumatic, nontraumatic or idiopathic and spontaneous. The nonspecific initial clinical presentation is followed by discomfort in the lower abdomen, oliguria, hematuria and ascitis. Laboratory abnormalities simulate the picture of acute renal failure and occurs by a mechanism called auto reverse dialysis, with absorption of excreta through the peritoneal membrane. The authors describe a case of bladder rupture in morphologically and functionally normal urinary bladder associated with alcohol intake in young healthy man, manifested by abdominal discomfort, pseudo renal failure and massive ascitis. The diagnosis was made by an abdominal multidetector computed tomography confirmed by the finding of $7 \mathrm{~cm}$ laceration at laparotomy.

Keywords: Urinary bladder; Dialysis; Renal insufficiency; Ascitis.

\footnotetext{
${ }^{a}$ Divisão de Clínica Médica do Hospital Universitário - Universidade de São Paulo, São Paulo/SP - Brasil.

b Hospital das Clínicas da Faculdade de Medicina - Universidade de São Paulo, São Paulo/SP - Brasil.

${ }^{c}$ Serviço de Imagenologia do Hospital Universitário - Universidade de São Paulo, São Paulo/SP - Brasil.

d Divisão de Clínica Cirúrgica do Hospital Universitário - Universidade de São Paulo, São Paulo/SP - Brasil.
}

Copyright () 2011 Autopsy and Case Reports - Este artigo de Acesso Aberto é distribuído pelos termos do Creative Commons Attribution NonCommercial License (http://creativecommons.org/licenses/by/3.0/) que permite livre uso não-comercial, distribuição e reprodução em qualquer meio, desde que os artigos sejam devidamente citados. 


\section{RELATO DO CASO}

Homem, 34 anos, natural da Bahia, previamente hígido, procurou pronto socorro com queixa de dor abdominal difusa, associada a náuseas com piora progressiva há 6 dias. Referia aumento progressivo do volume abdominal, anorexia, oligúria e um episódio de hematúria. Negava febre. Referia grande ingesta alcoólica e queda da própria altura no dia anterior ao quadro de dor abdominal. Tem passado de ser etilista há 16 anos e tabagista de 16 maços-ano. Ao exame físico apresentava abdome distendido, doloroso, com ascite volumosa, sem sinal de descompressão brusca.

Os exames iniciais (Tabela 1) revelaram leucocitose com desvio até mielócitos, hipercalemia, hiponatremia e insuficiência renal. A radiografia simples de abdome evidenciava borramento da gordura pré peritoneal, opacificação homogênea do abdome com deslocamento medial das alças intestinais, compatível com a presença de ascite (Figura 1). O exame de ultrassonografia abdominal mostrou ascite volumosa com ecos em suspensão, sem nenhuma evidência de hepatopatia, nefropatia ou obstrução das vias urinárias.

O exame de urina tipo 1 evidenciou proteinúria +++ , glicosúria + e hematúria ++ , leucocitúria superior a 1 milhão de leucócitos. $\mathrm{mL}^{-1}$ e hematúria de 136000 hemácias. $\mathrm{mL}^{-1}$, sem cilindros ou cristais.
A proteinúria de 24 horas foi de $1846 \mathrm{mg}$. Exames protoparasitológicos com pesquisa de Schistosoma mansoni foram negativos.

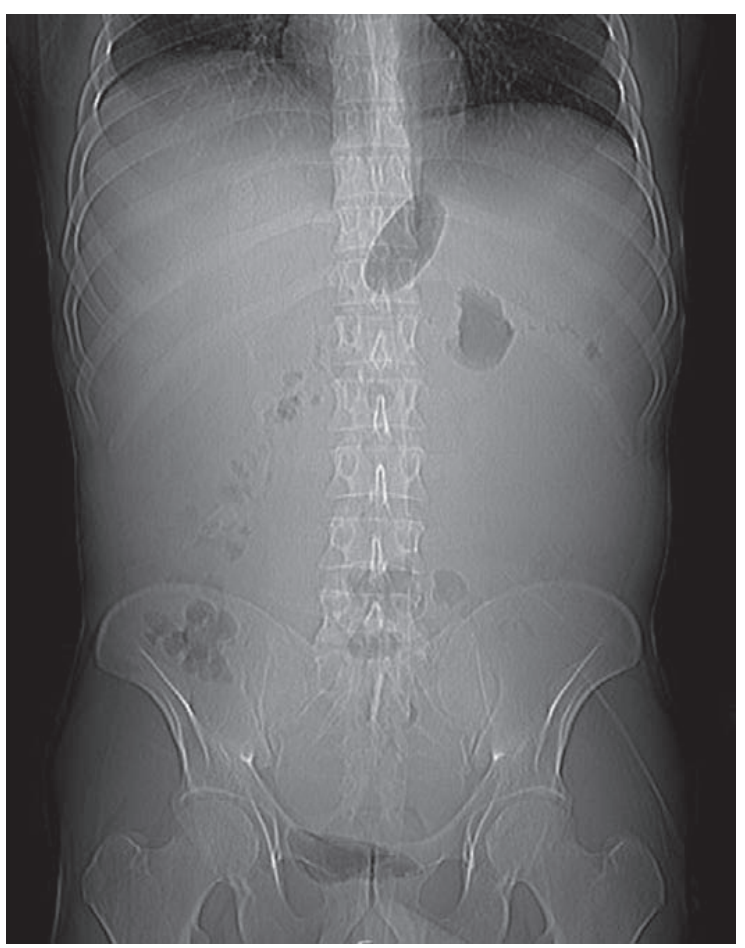

Figura 1 - Radiografia simples de abdome. Borramento da gordura pré peritoneal, opacificação homogênea do abdômen com deslocamento medial das alças intestinais, compatível com a presença de ascite.

Tabela 1 - Principais exames laboratoriais do paciente na entrada, e no $10^{\circ}$ pós-operatório (alta)

\begin{tabular}{|c|c|c|c|c|c|c|c|}
\hline Exames & VR & Do & Alta & Exames & VR & Do & Alta \\
\hline Uréia & $10-50 \mathrm{mg} \cdot \mathrm{dL}^{-1}$ & 286 & 18 & AST & $10-31$ U. $L^{-1}$ & 38 & - \\
\hline Creatinina & $0,4-1,3 \mathrm{mg} \cdot \mathrm{dL}^{-1}$ & 11,1 & 0,5 & ALT & $9-36 \cup . L^{-1}$ & 131 & - \\
\hline Sódio & $136-146 \mathrm{mEq} \cdot \mathrm{L}^{-1}$ & 124 & 134 & Bil. total & $0,3-1,2 \mathrm{mg} \cdot \mathrm{dL}^{-1}$ & 0,4 & - \\
\hline Potássio & $3,5-5,0$ mEq. $\mathrm{L}^{-1}$ & 7,3 & 4,1 & Amilase & 20-104 U.L-1 & 74 & - \\
\hline Hemoglobina & $12,3-15,3 \mathrm{~g} \%$ & 17,7 & 11,3 & F. Alcalina & $10-100$ U.L-1 & 136 & - \\
\hline Hematócrito & $36-45 \%$ & 53 & 34 & Gama GT & $2-30$ U.L-1 & 237 & - \\
\hline Leucócitos & $4400-11300 \cdot \mathrm{mm}^{-3}$ & 17600 & 5100 & Prot. totais & $6-8 \mathrm{~g} \cdot \mathrm{dL}^{-1}$ & 9,3 & - \\
\hline Mieló/mtmielo & $0 / 0 \%$ & $1 / 8$ & & Albumina & $3-5 \mathrm{~g} \cdot \mathrm{dL}^{-1}$ & 5,2 & \\
\hline Bastonetes & $1-5 \%$ & 2 & 0 & INR (TP) & 1 & 1,08 & - \\
\hline Segmentados & $45-70 \%$ & 84 & 58 & $\mathrm{R}$ (TTPA) & 1 & 1,2 & - \\
\hline Eosinófilos & $1-4 \%$ & 0 & 9 & C4 & $10-40 \mathrm{mg} \cdot \mathrm{dL}^{-1}$ & 49 & - \\
\hline Basófilos & $0-2,5 \%$ & 0 & 1 & C3 & $90-180 \mathrm{mg} \cdot \mathrm{dL}^{-1}$ & 214 & \\
\hline Linfócitos & $18-40 \%$ & 8 & 22 & FAN & NR & $N R$ & \\
\hline Monócitos & $2-9 \%$ & 4 & 10 & F. Reumatóide & $<15$ Ul. $\mathrm{mL}^{-1}$ & $<15$ & \\
\hline Plaquetas & $150-400 \cdot 10^{3} \cdot \mathrm{mm}^{-3}$ & 662000 & 325000 & & & & \\
\hline
\end{tabular}

Do = dia da admissão, $V R=$ valores de referência, $N R=$ não reagente. 
A paracentese mostrou albumina de $0,4 \mathrm{~g} \cdot \mathrm{dL}^{-1}$ (gradientesoro-ascitedealbumina $(\mathrm{GASA})=4,8 \mathrm{~g} \cdot \mathrm{dL}^{-1}$ ), 73 células $\mathrm{mm}^{-3} \mathrm{com}$ predomínio linfomononuclear, $\mathrm{DHL}=69 \mathrm{U} \cdot \mathrm{L}^{-1}$, glicose $=115 \mathrm{mg} \cdot \mathrm{dL}^{-1}, \mathrm{ADA}=1,6 \mathrm{U} \cdot \mathrm{L}^{-1}$. A coloração de Gram, a pesquisa de bacilo álcoolácido resistente, a citologia oncótica em amostra de $100 \mathrm{~mL}$ de líquido ascítico e as culturas foram todas negativas. A sorologia anti-HIV ELISA foi positiva e as sorologias para hepatite $A, B$ e $C$ e sifilis foram negativas.

O paciente recebeu ceftriaxone por 7 dias, para possível infecção urinária mantendo oligúria e ascite refratária à restrição hídrica e diuréticos. Submetido a sessões de hemodiálise a cada 2 dias sem mostrar melhora das dosagens de uréia e creatinina e tampouco da redução do volume da ascite, que por sua vez parecia aumentar causando dor abdominal e dispnéia, impondo paracenteses de alívio.

A tomografia, realizada com o objetivo de procurar uma causa que pudesse explicar a ascite revelou inesperadamente a rotura da parede vesical confirmada com a injeção de contraste na bexiga via sonda vesical (Figuras 2-4).

Após a passagem da sondagem vesical, o paciente iniciou diurese abundante (o débito da sonda foi de $6 \mathrm{~L}$ no primeiro dia), redução progressiva e rápida da ascite e dos níveis de uréia e creatinina, não mais indicando a necessidade de hemodiálise. Com este diagnóstico foi submetido à laparotomia para sutura da lesão vesical que se mostrou ser de aproximadamente $7 \mathrm{~cm}$. $\mathrm{O}$ aspecto da parede vesical era normal. Em 72 horas já não apresentava ascite nem alterações de exames laboratoriais sugestivos de insuficiência renal (Gráfico 1). Em 10 dias a sonda vesical foi retirada e o paciente recebeu alta hospitalar. O diagnóstico final foi o de rotura da bexiga espontânea, com uroascite e pseudo insuficiência renal.

\section{DISCUSSÃO}

O caso relatado é de um homem jovem, previamente hígido, etilista e procedente de região endêmica para esquistossomose, com os diagnósticos sindrômicos de: ascite e Insuficiência renal aguda. Em relação à ascite, foi considerada a hipótese de doença hepática, baseada na história de etilismo. Porém não havia sinais clínicos de hepatopatia crônica ou insuficiência hepática nem

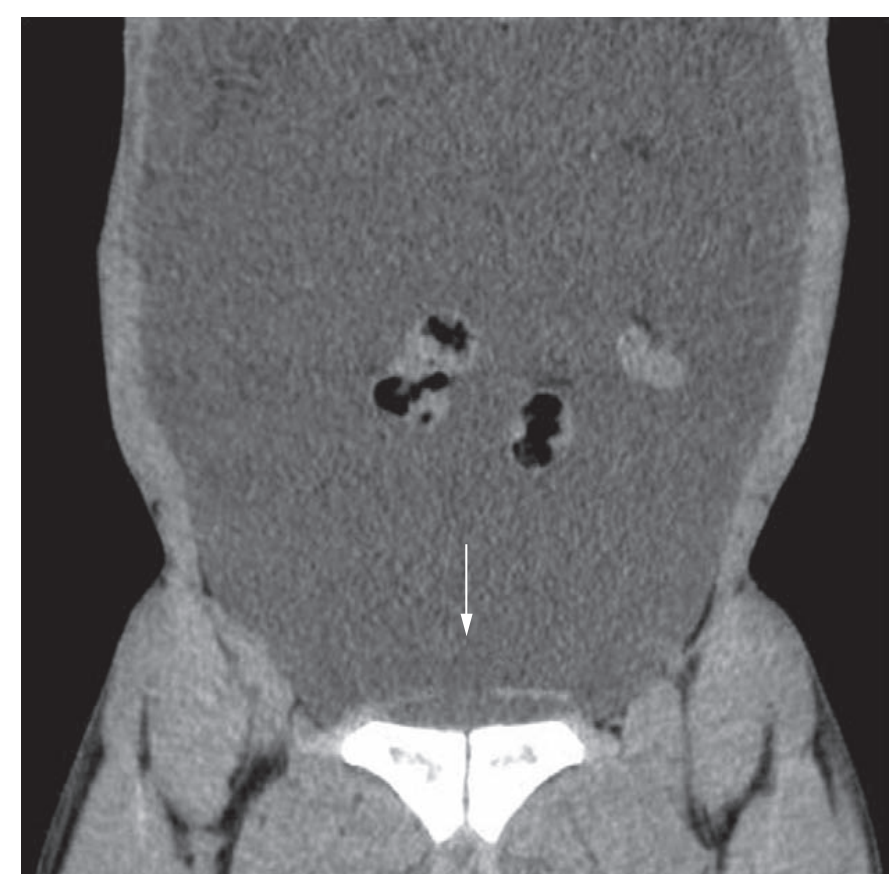

Figura 2 - Tomografia de abdome. Rreconstrução sagital sem contraste evidenciando perda de continuidade da parede vesical e ascite volumosa.

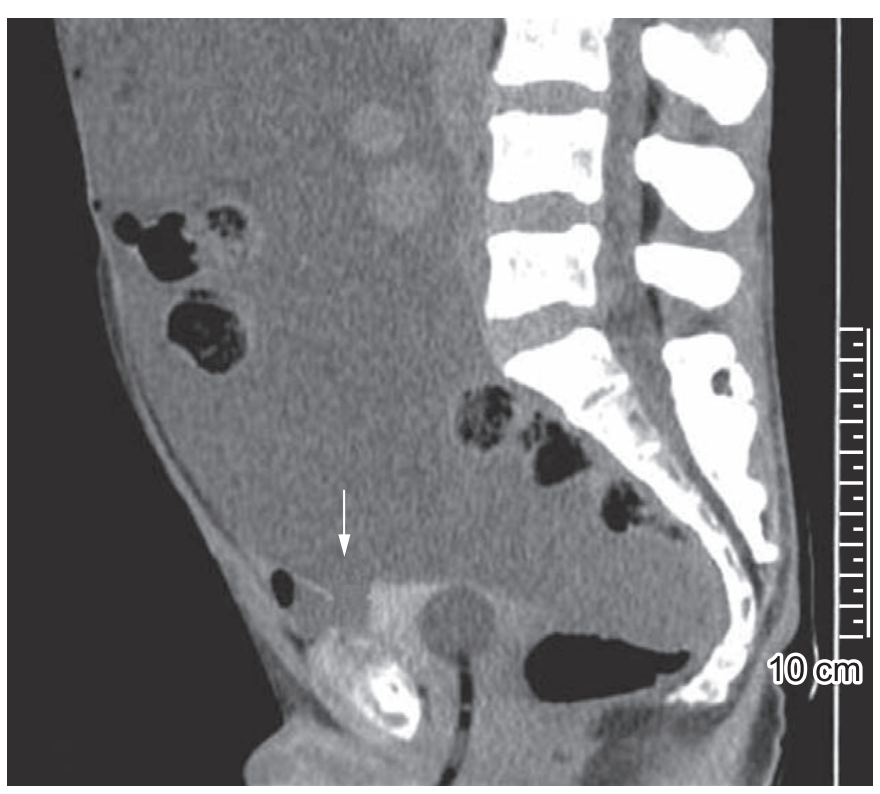

Figura 3 - Tomografia de abdome. Reconstrução coronal mostrando a perda da continuidade da parede vesical (seta).

tampouco os exames de imagem e laboratoriais favoreciam esta hipótese a exceção do gradiente soro ascite de albumina que mostrava o padrão encontrado na hipertensão portal. Outras causas de hipertensão portal, esquistossomose, hepatites, uso de drogas e medicamentos, foram afastadas. Em relação à insuficiência renal, causava estranheza a ausência de qualquer sintomatologia 

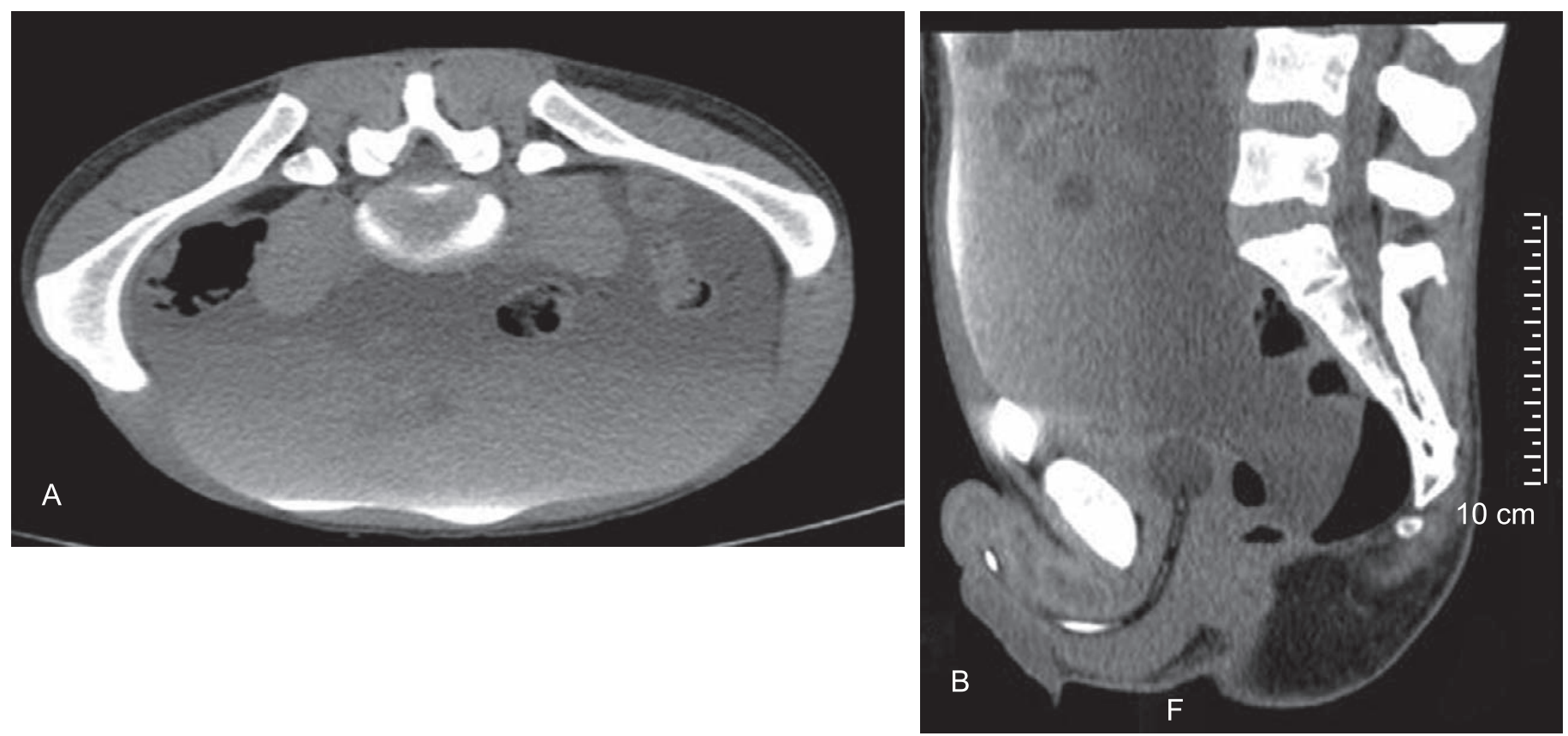

Figura 4 - Tomografia Computadorizada do Abdome. A - corte axial com o paciente em decúbito ventral. Notar extravasamento do contraste no líquido ascítico após injeção do contraste por sonda vesical. Observar acúmulo do contraste na porção anterior do abdome; B - reconstrução coronal. Observar sonda vesical posicionada e a hiperatenuação do líquido ascítico após injeção do contrastre.

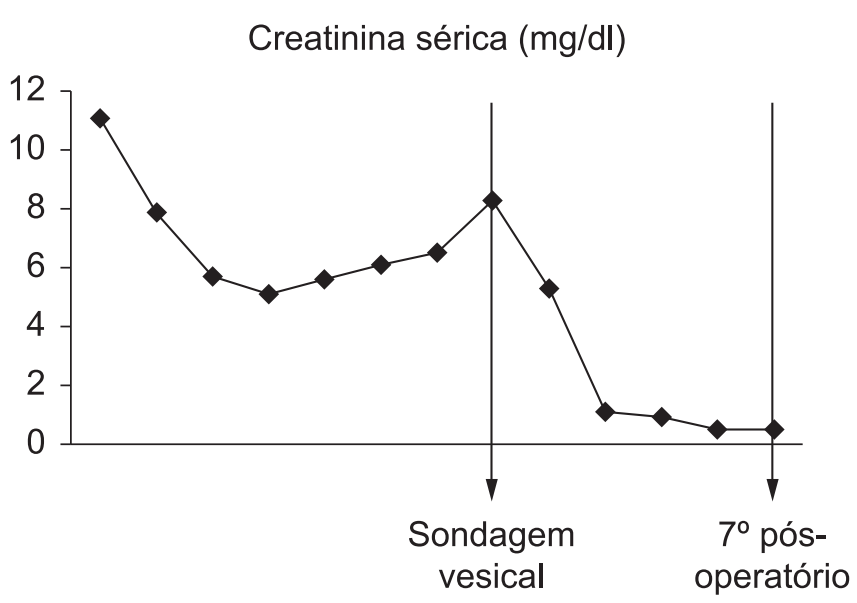

Gráfico 1 - Evolução dos níveis de creatinina durante a internação

de uremia. O hematócrito elevado não era compatível com nefropatia crônica. Os achados na urina tipo 1 de hematúria, proteinúria e leucocitúria poderiam sugerir lesão glomerular aguda ou subaguda, inclusive podendo estar relacionada ao HIV, recentemente detectado. O ultrassom de vias urinárias era normal. Foram investigadas patologias renais auto-imunes que resultaram negativas. Procurávamos pensar num único diagnóstico que explicasse à insuficiência renal e a ascite volumosa quando o resultado da tomografia de abdome finalmente fez o diagnóstico.
A maioria das roturas da bexiga é de origem traumática incluindo trauma abdominal, relacionado a procedimentos urológicos ou obstétricos, uso de catéteres de longa permanência e dispositivos intra-uterinos. Há ainda a rara ocorrência de lesão vesical associada à fratura espontânea do púbis na osteoporose grave. ${ }^{1} \mathrm{~A}$ rotura não traumática ou espontânea é mais rara apresentando incidência de 1 para 126.000 admissões hospitalares. ${ }^{2}$ As roturas espontâneas da bexiga estão associadas à presença de patologia da bexiga ou à complicação de retenção urinária. ${ }^{3}$ Dentre as patologias da bexiga que podem cursar com rotura/perfuração encontramse: a) cistites inflamatórias (pós quimioterapia e relacionada ao lúpus ou ao uso de ciclofosfamida), b) cistites infecciosas (fungica, tuberculose, cistite enfisematosa, esquistossomíase), c) lesão da parede vesical após radioterapia pélvica (há relatos de rotura vesical mesmo após 40 anos da radioterapia), d) divertículo, e) neoplasia e f) cicatriz cirúrgica da bexiga. ${ }^{2}$ Entre as causas de rotura vesical por retenção urinária (causas obstrutivas), podemos citar: cálculo vesical gigante, herniação da bexiga para a região ínguino escrotal, fecaloma e obstruções uretrais. ${ }^{4} \mathrm{~A}$ rotura não traumática ocorrendo numa bexiga normal é chamada de rotura vesical idiopática. Grande parte destes casos parece estar relacionada com o abuso de álcool. ${ }^{3}$ Nestes casos, o efeito diurético do álcool somado a alteração do sensório reduzindo à percepção 
da necessidade de urinar acarreta hiperdistensão da bexiga. A bexiga hiperdistendida geralmente rompe numa região mais fina e mais fraca da parede vesical denominada "domus". Esta região, mais susceptível à rotura, se rompe por súbito aumento da pressão intravesical ou intra-abdominal ocasionados por: traumatismos (geralmente não lembrados pelo paciente), crises convulsivas ou mesmo por vômitos. Além da associação com o etilismo, há ainda relatos de casos de rotura vesical associada à intoxicação por opióides, em pacientes com bexiga neurogênica e durante o parto normal em gestantes com a bexiga cheia. ${ }^{5}$

A maior série de relatos de casos de rotura espontânea de bexiga foi registrada por Bastable et al. em 1959. ${ }^{6} \mathrm{~A}$ maioria destes casos ocorreu em pacientes com patologia vesical ou com obstrução do trato urinário inferior. A mortalidade referida nessa série era em torno de $50 \%$. Hoje, com a melhoria das técnicas de abordagem da septicemia e da hipercalemia e do desenvolvimento de técnicas que permitem diagnóstico mais precoce, a mortalidade é menor porem, a morbidade permanece alta nos registros recentes de pseudo insuficiência renal $^{7}$ e de pseudo infarto do miocárdio ${ }^{8}$. Entende-se por pseudo infarto do miocárdio as alterações eletrocardiográficas decorrentes das alterações metabólicas, como alargamento dos complexos QRS e elevações do segmento $\mathrm{ST}^{3} \mathrm{O}$ diagnóstico desta rara doença é difícil, especialmente no início da apresentação, quando os sinais e sintomas clínicos são escassos ou inespecíficos. Em geral, o paciente procura o serviço médico por dor ou desconforto em abdome inferior, oligúria e hematúria. Na evolução ele poderá apresentar distensão abdominal por ascite, íleo paralítico e peritonismo. ${ }^{4} \mathrm{O}$ alívio da dor abdominal e da distensão abdominal após passagem da sonda vesical de demora deve levantar a possibilidade de rotura vesical. Lembremos que a presença de urina na cateterizacão vesical não afasta a possibilidade de rotura. ${ }^{4}$

Os achados laboratoriais mais frequentes serão:leucocitoseleveamoderada, elevaçãodauréia e da creatinina séricas, hipercalemia, hiponatremia, acidose metabólica com hipercloremia e anion gap normal, albumina normal e hipocalcemia. ${ }^{9,10}$ As alterações laboratoriais simulam o quadro de insuficiência renal aguda e ocorrem pelo mecanismo chamado de auto diálise reversa, com absorção de excretas através da membrana peritoneal que costuma ocorrer 24 horas após o extravasamento da urina para dentro da cavidade peritoneal. ${ }^{11} \mathrm{~A}$ análise do líquido peritoneal revela aspecto amarelo claro, semelhante à urina, exibindo gradiente entre a albumina do líquido ascítico e do soro (GASA) $>1$ (falsa hipertensão portal) e concentrações de uréia e creatinina muito elevadas alertando para o diagnóstico de uroascite. A relação de creatinina da ascite/creatinina sérica $>1,0$ é fortemente sugestiva de uroascite. A elevada concentração de creatinina no líquido ascítico é causada pela menor taxa de remoção de macromoléculas e fluido intraperitoneal pelos linfáticos subdiafragmáticos comparado com a taxa de acúmulo de líquido nesta cavidade. No exame de urina tipo 1 haverá hematúria, proteinúria e leucocitúria. ${ }^{12,13}$ O diagnóstico na maioria dos casos é confirmado por cistografia retrógrada ou tomografia abdominal. O ultrassom abdominal com doppler e a cistografia contrastada convencional podem também auxiliar no diagnóstico. ${ }^{4,14}$

A maioria das roturas será intraperitoneal e o tratamento deve ser cirúrgico para rafia da bexiga. Após o tratamento cirúrgico, é recomendada a educação do paciente, incluindo treinamento vesical e estudos urodinâmicos para excluir qualquer obstrução urinária baixa. ${ }^{15}$ Nos casos em que a perfuração é extra peritoneal, em geral é possível o tratamento conservador, apenas com passagem de sonda vesical de demora. ${ }^{3,15}$

A suspeita clínica é necessária para o diagnóstico de rotura de bexiga, principalmente nos "pacientes de risco" com sintomas abdominais, sinais de ascite e/ou íleo, hematúria, diminuição do débito urinário e exames bioquímicos compatíveis com insuficiência renal, uma vez afastadas as causas mais comuns de ascite. No caso relatado a tomografia computadorizada com multidetectores de abdome foi fundamental para o diagnóstico.

Neste caso o diagnóstico não foi precoce porque, alem de não ter sido lembrada a hipótese de uroascite, havia outros dados que conduziram a raciocínio clínico diverso. Na literatura há também relato de paciente submetido a diálise e biópsia renal, que por ser diabético recebeu diagnóstico de nefropatia diabética ${ }^{12}$ antes do diagnóstico de uroascite.

Clínicos e emergencistas devem estar atentos para este diagnóstico raro, mas reversível quando precoce. O diagnóstico tardio pode resultar em abscesso intra-abdominal e pélvico, septicemia, iatrogenias e óbito. 


\section{REFERÊNCIAS}

1. Dotchin C, Colman A, Shanshal Y. Bladder rupture following osteoporotic pubic ramus and sacral insufficiency fractures. Age Ageing. 2010;39(4):430-8. PMid:20494898. http://dx.doi.org/10.1093/ageing/afq046

2. Lynn SJ, Mark SD, Searle M. Idiopathic spontaneous bladder rupture in an intoxicated patient. Clin Nephrol. 2003;60(6):430-2. PMid:14690262.

3. Parker H, Hoonpongsimanont W, Vaca F, Lotfipour S. Spontaneous bladder rupture in association with alcoholic binge: a case report and review of the literature. J Emerg Med. 2009;37(4):386-9. PMid:17976802. http://dx.doi. org/10.1016/j.jemermed.2007.03.049

4. Sezhian V, Rimal D, Suresh G. Isolated Intraperitoneal bladder rupture following minor trauma after alcohol ingestion. South Med J. 2005;98(5):573-4. PMid:15954519. http://dx.doi.org/10.1097/01.SMJ.0000157533.91138.33

5. Galbraith JG, Butler JS, MCGreal G. Opioid toxicity as a cause of spontaneous urinary bladder rupture. Am J Emerg Med. 2011;29(2):239. e 1-3.

6. Bastable FRCS, De Jode FRCS, Warren FRCS. Spontaneous rupture of the bladder. $\mathrm{Br} J$ Urol. 1959:31(1):78-86. PMid:13651652. http://dx.doi.org/10.1111/j.1464-410X.1959. tb09386.x

7. Wystrychowski A, Nowicki M, Kokot F. Hyponatraemic renal pseudofailure - don't forget the possibility of uroperitoneum. Nephrol Dial Transplant. 1996;11(12): 2491-2. PMid:9017630
8. Ortega-Carnicier J, Alcazar R, Ambros A, et al. Acute postrenal failure and pseu http://dx.doi.org/10.1007/ s001340051163domyocardial infarction after spontaneous bladder rupture. Intensive Care Med. 2000;26(3):353- 4. http://dx.doi.org/10.1007/s001340051163

9. Vohra SB, Kapur S. Diagnosis of bladder rupture by arterial blood gas analysis. Anaesthesia. 2007;62(5):534-5. http://dx.doi.org/10.1111/j.1365-2044.2007.05075_13.x

10. Horino T, Okazaki M, Nishikawa H, Takao T, Taniguchi $\mathrm{Y}$, Morita $\mathrm{T}$, et al. A case with spontaneous bladder rupture mimicking acute kidney injury. Clin Nephrol. 2009;72(5):391-3.

11. Yeh HC, Ting IW, Huang WY, Huang JW. The case mid $\mathrm{R}$ : ascites with oliguric acute renal failure. Kidney Int. 2008;74(2):249-50.

12. Manna R, Mirk P, Sallustio G, Brisinda G, Izzi D, La Regina $M$, et al. Hypercreatininemia and hyperglycemia: diabetic nephropathy or "inverted peritoneal auto-dialysis"? Clin Nephrol. 2005;63(2):167-9

13. Jayathillake A, Robinson R, Al-Samarii A, Manoharan M. Spontaneous rupture of bladder presenting as peritonitis. N Z Med J. 2002;115(1164):U222.

14. Okafor CN, MD, Gupta M. Acute Kidney Injury PostCesarean Delevery: is GFR reduced? Am J Kidney Dis. 2008;52(2):A37-9.

15. Sharma A, Teh B, Morgan DJR, et al. When ascites is not ascites. Postgrad Med J. 2008;84(995);502-3. http://dx.doi. org/10.1136/pgmj.2008.068833. doi:10.1136/pgmj.2008.068833

Conflito de interesse: Não há.

Submetido em: 2 de Agosto de 2011

Aceito em: 18 de Agosto de 2011

Correspondência: Divisão de Clínica Médica

Av. Prof. Lineu Prestes, 2565, Cidade Universitária - São Paulo/SP - Brasil

CEP: 05508-000 - Tel.: +55 (11) 3091-9200

E-Mail: lucianaavena@hu.usp.br 